\title{
A Postharvest Fruit Rot in Apple Caused by Phacidiopycnis washingtonensis
}

\author{
Y. K. Kim and C. L. Xiao, Department of Plant Pathology, Washington State University, Tree Fruit Research and \\ Extension Center, 1100 N. Western Avenue, Wenatchee, WA 98801
}

\begin{abstract}
Kim, Y. K., and Xiao, C. L. 2006. A postharvest fruit rot in apple caused by Phacidiopycnis washingtonensis. Plant Dis. 90:1376-1381.

During a survey of postharvest diseases in Red Delicious apples (Malus domestica) conducted in 2003, a previously undescribed postharvest fruit rot was discovered in Washington State. The causal agent has been described as a new species, Phacidiopycnis washingtonensis. In this study, we described the symptomatology of this disease, determined its occurrence and prevalence in Washington State, tested pathogenicity, and determined infection courts on fruit of three apple varieties. Decayed fruit were sampled from 26, 72, and 81 grower lots during March to August in 2003, 2004, and 2005, respectively, during packing operations from commercial packinghouses. Symptoms of decayed fruit were recorded and isolations were made from decayed fruit to correlate causal agents with the disease symptoms observed. Fruit of Red Delicious, Golden Delicious, and Fuji apples were inoculated in the orchards with conidial suspensions of the fungus at 1 and 2 weeks before harvest. All fruit were harvested and stored at $0^{\circ} \mathrm{C}$, and decay development on the fruit was monitored monthly for up to 9 months. The symptoms were primarily stem-end rot and calyx-end rot. Infection also occurred at lenticels on fruit skin, particularly on Golden Delicious. The decayed area was spongy to firm and appeared light brown to brown. On Red Delicious, brown to black specks at lenticels often appeared at the decayed area as the disease advanced. This disease occurred in 23,26 , and $17 \%$ of the total grower lots, accounting for approximately 1, 4, and 3\% of the total decay in 2003, 2004, and 2005, respectively. In 2004 and 2005, severe losses of fruit were observed in three grower lots of Red Delicious, and their losses were as high as $24 \%$. After 9 months in storage, 48 , 48, and $24 \%$ of Red Delicious, Golden Delicious, and Fuji that were inoculated in the orchards, respectively, developed symptoms of this disease, and the fungus was reisolated from decayed fruit. Stem-end rot was common on Red Delicious and Golden Delicious, whereas calyx-end rot was common on Fuji. We propose "speck rot" as the name of this disease.
\end{abstract}

Additional keywords: postharvest decay, postharvest pathology

Washington State is the leading producer of fresh apples (Malus domestica) in the United States. In 2004, apple production in Washington State accounted for $58 \%$ of the U.S. total, and its value was approximately $\$ 962$ million (7). Apple production occurs primarily in the central part of the state. Red Delicious, Fuji, and Golden Delicious are among the major apple varieties, accounting for 43,13 , and $12 \%$ of the total acreage, respectively (6). Varieties differ in time to maturity. Apple harvest starts in mid-August and may not finish until early November, depending on varieties. At harvest, fruit are placed into wooden or plastic bins (approximately 400 $\mathrm{kg}$ of fruit per bin), and bins are then

Corresponding author: C. L. Xiao

E-mail: clxiao@wsu.edu

Accepted for publication 23 June 2006.

DOI: 10.1094/PD-90-1376

(C) 2006 The American Phytopathological Society transported into storage and packing facilities. Fruit are stored in field bins in regular atmosphere (RA) for short-term storage and in controlled atmosphere (CA) (1 to $2 \% \mathrm{O}_{2}$ and $0.5 \% \mathrm{CO}_{2}$ ) at -1 to $0{ }^{\circ} \mathrm{C}(5)$ for long-term storage until packing. Because fruit may remain in field bins for up to 10 to 12 months in storage, during which time fruit rot diseases may develop, postharvest fruit rot diseases are considered a limiting factor for the long-term storage of apples (13).

Several postharvest diseases commonly occur on apples in Washington State, including blue mold caused by Penicillium spp., primarily $P$. expansum Link, gray mold caused by Botrytis cinerea Pers., Sphaeropsis rot caused by Sphaeropsis pyriputrescens Xiao \& J.D. Rogers, and bull's eye rot caused by Neofabraea spp. $(4,13,16,17)$. In Washington State, Phacidiopycnis rot caused by Phacidiopycnis piri (Fuckel) Weindlmyr, anamorph of the discomycete Potebniamyces pyri (Berkeley \& Broome) Dennis, has recently been reported on pears (14). Phacidiopycnis rot is one of the major postharvest fruit rots in d'Anjou pears in Washington State (14), but it is much less common on apples (Y. K. Kim and C. L. Xiao, unpublished).

During a preliminary survey of postharvest diseases of Red Delicious apples conducted in the 2002-2003 storage season, a previously undescribed fruit rot disease was observed on stored apples. The typical symptoms on apples during storage were stem-end rot and calyx-end rot. The causal agent of this disease has been described as a new species, Phacidiopycnis washingtonensis Xiao \& J.D. Rogers (18), but details about symptomatology, pathogenicity, and infection courts on apple fruit, and its occurrence and prevalence in Washington State, have not been described.

The objectives of this study were to (i) describe a new postharvest fruit rot disease of apple caused by Phacidiopycnis washingtonensis, (ii) determine the prevalence and incidence of this disease on three major apple varieties in Washington State, and (iii) test pathogenicity of the fungus and determine its infection sites on apple fruit.

\section{MATERIALS AND METHODS}

Symptoms, prevalence, and incidence of the disease in storage. Surveys of postharvest diseases on apples were conducted during apple storage from June to August 2003 and from March to August in 2004 and 2005. Decayed apple fruit were sampled from six commercial packinghouses, representing orchards in various appleproducing areas including north-central Washington, the Columbia Basin, and the Yakima Valley area. Approximately 50 decayed fruit from each grower lot were randomly sampled from cull bins or sorting tables during packing or presizing operations. In this study, each grower lot represents one orchard. Twenty-six grower lots of Red Delicious were collected from June to August in 2003; 72 grower lots (39 Red Delicious, 19 Golden Delicious, and 14 Fuji) and 81 grower lots (37 Red Delicious, 19 Golden Delicious, and 25 Fuji) were collected from March to August in 2004 and 2005, respectively. Samples were sorted by symptoms and the presence of wounds. Color of decayed areas and type of decay (soft or watery decay versus firm or spongy decay) also were recorded. Photos of decayed fruits were taken before 
isolation in order to correlate causal agents with the disease symptoms observed.

Isolation of the causal agent. To determine causal agents of fruit rots, isolations were made from all fruit without the presence of sporulation or fruiting bodies of decay-causing pathogens. Decayed fruit were sprayed with $70 \%$ ethanol and airdried in a biosafety hood. Fragments (approximately $5 \times 5 \times 3 \mathrm{~mm}^{3}$ ) of decayed fruit were removed with a sterile scalpel from the margin of diseased and healthy tissue and aseptically placed on acidified potato dextrose agar (APDA) (4 $\mathrm{ml}$ of a $25 \%$ lactic acid solution into 1 liter of PDA). Plates were incubated at $20^{\circ} \mathrm{C}$ in the dark and examined for culture development. Fungi that grew on APDA were transferred onto fresh APDA. Pure cultures were then grown on PDA, and mycelium plugs were stored in $15 \%$ glycerol at $-80^{\circ} \mathrm{C}$ for future use. Identification of $P$. washingtonensis was based upon the descriptions of the fungus by Xiao et al. (18). $P$. washingtonensis and $P$. piri were differentiated based upon the differences in morphology and growth characteristics on agar media described by Xiao et al. (18).

Pathogenicity tests. Fruit of Red Delicious, Golden Delicious, and Fuji were inoculated in orchards to test pathogenicity of $P$. washingtonensis and to determine infection sites on fruit. The experiments were conducted in research orchards of Red Delicious and Golden Delicious located at the Tree Fruit Research and Extension Center, Washington State University, Wenatchee, and in a Fuji research orchard in Orondo, WA. Isolate CLX2152, recovered from a decayed Red Delicious fruit sampled from a commercial packinghouse, was used in this study. The voucher specimen from which isolate CLX2152 was derived is deposited at the Washington State University Mycological Herbarium (accession no. WSP 71071), and the living culture is maintained at ATCC (accession no. MYA-3320). For inoculum preparation, the isolate was reactivated from a stored culture at $-80^{\circ} \mathrm{C}$ and grown on PDA at $20^{\circ} \mathrm{C}$ for 2 weeks under 12 -h dark/12-h light. Oozing pycnidia were streaked on oatmeal agar (OMA, $60 \mathrm{~g}$ of iron- and zinc-fortified single-grain oatmeal [Gerber, Fremont, MI] with $15 \mathrm{~g}$ of agar in 1,000 $\mathrm{ml}$ of deionized water and sterilized for 90 $\min$ ), and the plates were placed at $20^{\circ} \mathrm{C}$ for 2 weeks under 12-h dark/12-h light. Each plate was flooded with $20 \mathrm{ml}$ of sterile water, and conidia were obtained by scraping oozing pycnidia. The resulting conidial suspensions were filtered through four layers of cheesecloth. The final concentration of conidial suspensions was adjusted to $1 \times 10^{5}$ conidia/ml with a hemacytometer.

Fifty fruit per replicate were selected for inoculation. Two trees of Red Delicious, three trees of Golden Delicious, and one tree of Fuji were used for each replicate.
There were three replicates for each variety. The fruit were inoculated with the conidial suspensions until runoff using a hand sprayer. Control fruit were sprayed with sterile water. The fruit were then covered with moistened plastic bags to maintain high humidity. Plastic bags were covered with white paper bags to prevent sunlight from generating damaging heat on fruit. All inoculations were conducted near sunset. After approximately $15 \mathrm{~h}$ of incubation, the bags were removed. During the incubation period, air temperature and relative humidity were recorded with a small data logger (Watchdog 450, Spectrum Technologies, Inc., Plainfield, IL). The experiments were conducted twice, at 2 weeks and 1 week before harvest. All fruit were harvested, transferred onto fiber foam apple-trays wrapped in perforated polyethylene bags, and stored in cardboard boxes at $0^{\circ} \mathrm{C}$ in RA. Decay development on the fruit, infection sites (stem, calyx, or lenticels) on the fruit, and percentage of the fruit with symptoms were recorded monthly after harvest for up to 9 months. Isolation was made from all decayed fruit to confirm the causal agent, following the procedure described above.

Statistical analysis. An $F$ test was used to determine if the variances of the two experimental runs in the orchards were homogeneous and if data could be pooled. If the homogeneity of variance test indicated that data from both runs could be pooled, the analysis was conducted on pooled data. Percentage of fruit with decay symptoms on three apple varieties at 9 months after harvest as well as percentage of decayed fruit initiating at different infection sites were subjected to analysis of variance using SAS PROC GLM (Version 8.2, SAS Institute, Cary, NC). The decay incidence data were arcsine-transformed prior to analysis. Mean separations were calculated based upon Fisher's protected least significant difference (LSD) $(P=$ $0.05)$.

\section{RESULTS}

Symptoms and isolation of causal agent. Symptoms of decayed fruit were primarily stem-end rot (Fig. 1A to C) and calyx-end rot (Fig. 1D to F). Infection also occurred at lenticels on fruit skin, but this type of symptom was not commonly seen on decayed fruit sampled from commercial fruit packinghouses. The decayed area was spongy to firm and appeared light brown to brown. On Red Delicious, brown to black specks at lenticels often appeared at the decayed area as the disease advanced. Specks often had light centers (Fig. 1B, G to I). The skin color of entire decayed Red Delicious varied and might appear light brown, brown, or pink with specks covering a part of or the entire fruit (Fig. 1G to I). The symptoms advanced along vascular tissues. When decayed fruit were cut, the internal decayed area appeared V- or U- shaped (Fig. 1C and F). The skin color on aged decayed areas often turned dark brown or black, especially after the fruit had been stored for an extended period of time (Fig. 1J). The fungus formed pycnidia on the surface of decayed fruit after an extended period in storage. Pycnidial formation usually started from infection sites. Pycnidia on decayed fruit were black and superficial or partially immersed (Fig. 1J).

P. washingtonensis was consistently isolated from decayed apple fruit with the symptoms described above. The colonies on APDA or PDA first appeared white and then light gray with fluffy aerial mycelium, and alternating rings of dark gray and light gray were evident in cultures, particularly on the reverse of petri plates. Black pycnidia of the fungus formed on 5to 7-day-old cultures starting from the center of the plate. Cream-colored oozing of conidia from pycnidia was commonly present in 1- to 2-week-old cultures grown at $20^{\circ} \mathrm{C}$ in the dark. Conidia were hyaline, lacriform with the dehiscence end flattened or ovoid to ellipsoid without the cicatrice, 6 to $7.5 \times 3$ to $4 \mu \mathrm{m}$. These observations were consistent with the descriptions of $P$. washingtonensis (18).

Prevalence and incidence of the disease. This new disease caused by $P$. washingtonensis occurred in 6 of 26 grower lots (23\%), accounting for $1 \%$ of the total decayed fruit in 2003; 19 of 72 grower lots (26\%), accounting for $4 \%$ of the total decayed fruit in 2004; and 14 of 81 grower lots (17\%), accounting for $3 \%$ of the total decayed fruit in 2005.

Decayed fruit were sampled from only Red Delicious in 2003 and from three major apple varieties of Red Delicious, Golden Delicious, and Fuji in 2004 and 2005. The percentage of grower lots infected by this disease varied among varieties. Over the 2 years (2004 to 2005), 36 and $25 \%$ of the total grower lots of Fuji and Red Delicious were infected, respectively. Only $5 \%$ of Golden Delicious lots were infected in 2004 and none in 2005 (Fig. 2). The percentage of this disease in the total decayed fruit also varied from grower lot to grower lot, ranging from 2 to $6 \%$ in 2003 (data not shown) and 2 to $93 \%$ in both 2004 and 2005 (Fig. 2). Instances of severe losses of fruit were observed on Red Delicious. In 2004, in two grower lots of Red Delicious, 78 and $93 \%$ of the decayed fruit were affected with this disease, which resulted in approximately 10 and $12 \%$ losses of the total fruit, respectively. In another grower lot of Red Delicious in 2005 , 93\% of the decayed fruit was affected with this disease, which resulted in $24 \%$ losses of the total fruit in storage bins after 7.5 months in storage (Fig. 1K). In other grower lots of Red Delicious infected by this disease, this disease accounted for low percentages of the total decay (Fig. 2). In the grower lots of Golden Delicious and Fuji infected by $P$. washingtonensis in both 

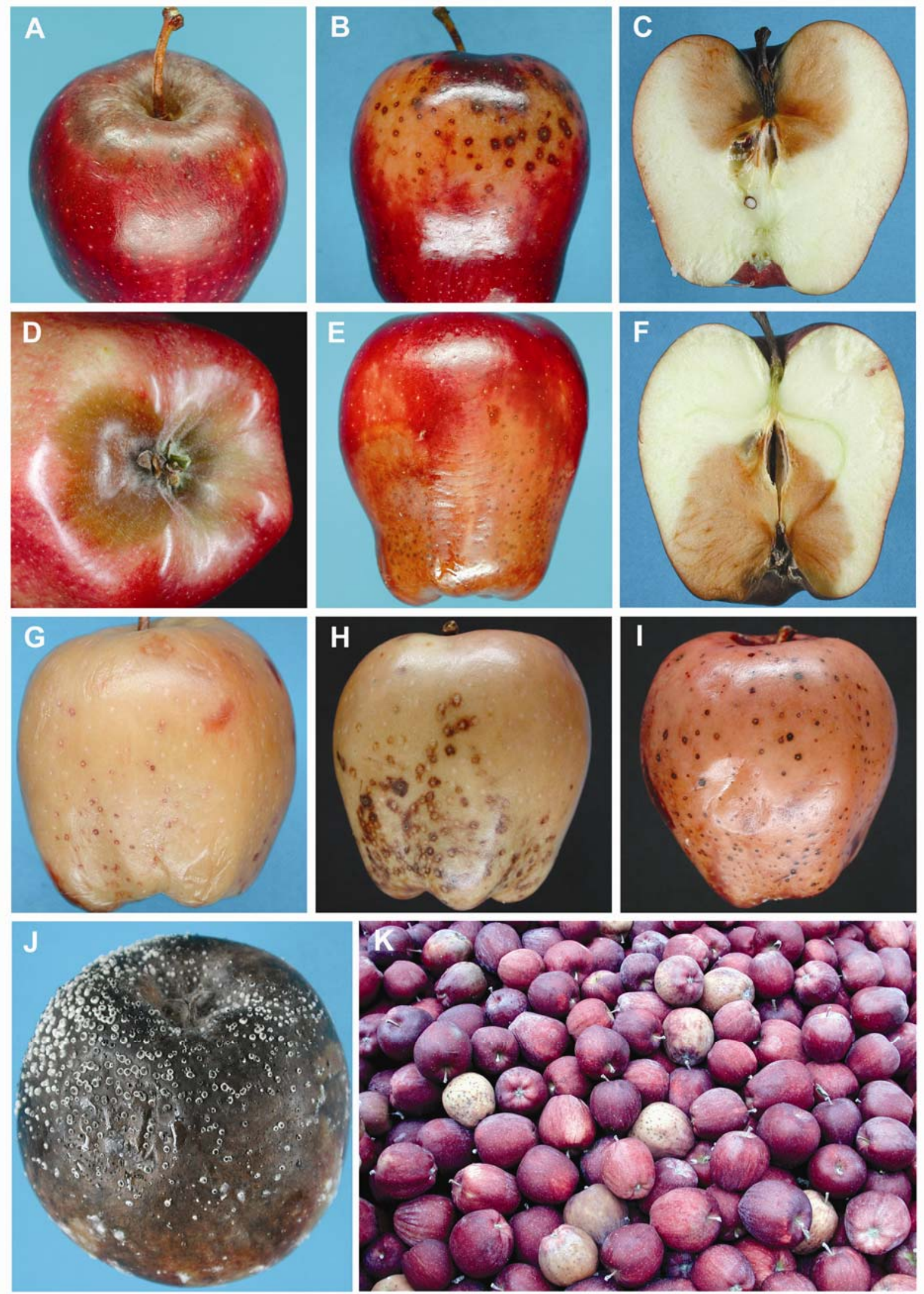

Fig. 1. Symptoms and signs of a fruit rot in apple caused by Phacidiopycnis washingtonensis. A, early stage of stem-end rot on a Red Delicious apple; B, advanced stage of stem-end rot on a Red Delicious apple with dark brown specks at lenticels at decayed area; $\mathbf{C}$, internal symptoms of stem-end rot; D, early stage of calyx-end rot on a Red Delicious apple; E, calyx-end rot with brown specks at the decayed area; F, internal symptoms of calyx-end rot; G-I, entire decayed fruit of Red Delicious varied in color and presence of specks at lenticels; J, entire fruit of Fuji decayed with pycnidia formed on the surface of the fruit after an extended period of time in storage; $\mathbf{K}$, in this grower lot of Red Delicious from a commercial fruit packinghouse, $24 \%$ of the fruit in storage bins were decayed by $P$. washingtonensis after 7.5 months in storage. 
2004 and 2005, this disease comprised less than 10 or $20 \%$ of the total decayed fruit, respectively.

Pathogenicity and infection courts. There was no significant difference in disease incidence between the two inoculations at 1 week and 2 weeks before harvest $(P>0.05)$, so pooled data are presented. The decay symptoms developed on all three varieties inoculated with conidial suspensions of $P$. washingtonensis and stored at $0^{\circ} \mathrm{C}$ in RA (Fig. 3). Symptoms were first observed at 2 months after harvest on Fuji and 3 months after harvest on Red Delicious and Golden Delicious. Disease incidence increased as the storage periods lengthened. At 9 months after harvest, Fuji had a significantly $(P=0.04)$ lower amount of fruit with decay symptoms in comparison with the other two varieties; $48 \%$ of Red Delicious, $48 \%$ of Golden Delicious, and 24\% of Fuji developed fruit rot symptoms. $P$. washingtonensis was reisolated from all decayed fruit. Because stem-end rot developed more slowly than calyx-end rot, stems of fruit without decay symptoms were cultured to confirm infections at stems. The incidences of fruit with stem infection, including decay-symptomless fruit, were 58 and $82 \%$ for Red Delicious and Golden Delicious, respectively. No stem infection was detected on the symptomless fruit of Fuji at 9 months after harvest. No decay was observed on fruit in the controls.

Infection of apple fruit by $P$. washingtonensis was initiated at three different sites: stem, calyx, and skin through lenticels (Fig. 4). The dominance of different infection sites was variety dependent $(P<$ $0.0001)$. At 9 months after harvest, symptoms on 67 and $59 \%$ of the decayed fruit of Red Delicious and Golden Delicious, respectively, appeared to result from infections of the stem of the fruit, whereas $68 \%$ of the decayed fruit of Fuji apparently originated from infections of calyx tissues of the fruit. Infections on fruit skin were 4, 31 , and $16 \%$ on Red Delicious, Golden Delicious, and Fuji, respectively.

\section{DISCUSSION}

In this study, we described a new postharvest fruit rot disease in apple caused by Phacidiopycnis washingtonensis. Over the 3-year survey of postharvest diseases on apple, this new disease occurred in 17 to $26 \%$ of the total grower lots we sampled, and the percentages of this disease in the total decayed fruit varied from grower lot to grower lot. Although this disease occurred sporadically, we observed a few instances of severe losses of Red Delicious apples caused by this disease during the storage seasons in 2004 and 2005. In these instances, losses of apple fruit in storage bins were as high as $24 \%$, indicating that this disease has the potential to cause significant economic losses of apple fruit during storage.
It is not known how long this disease has been present in Washington State, because no detailed surveys for postharvest diseases in apples have been reported since 1931. The previous survey of postharvest diseases in Washington apples was conducted in the late 1920 s $(2,9,10)$. Heald and Ruehle (2) reported that more than 40 species of fungi belonging to 22 genera were associated with fruit rots of apples in cold storage in Washington State. No Phacidiopycnis spp. were listed in Heald and Ruehle's report. Over the 3-year survey in the present study, we found that orchards from which infection of fruit by $P$. washingtonensis was observed were located in major apple-production counties across central Washington State, indicating that the fungus has become established in a large geographic area. Thus, it is possible that $P$. washingtonensis has been present in the region for a long time but has not previously been recognized. To date, there are two species of Phacidiopycnis listed as postharvest fruit-rotting pathogens on pome fruits. In addition to $P$. washingtonensis described here, Phacidiopycnis rot caused by Phacidiopycnis piri has recently been reported as an important postharvest disease of d'Anjou pears in Washington State (14). Phacidiopycnis rot also occurred on apples, but it was much less common on apple than on pear in Washington State (Y. K. Kim and C. L. Xiao, unpublished). The decayed area caused by $P$. piri on apple fruit was spongy and brown in the early stage, but the color varied with age. As the symptoms progressed, the decayed area turned black, which is different from the decay caused
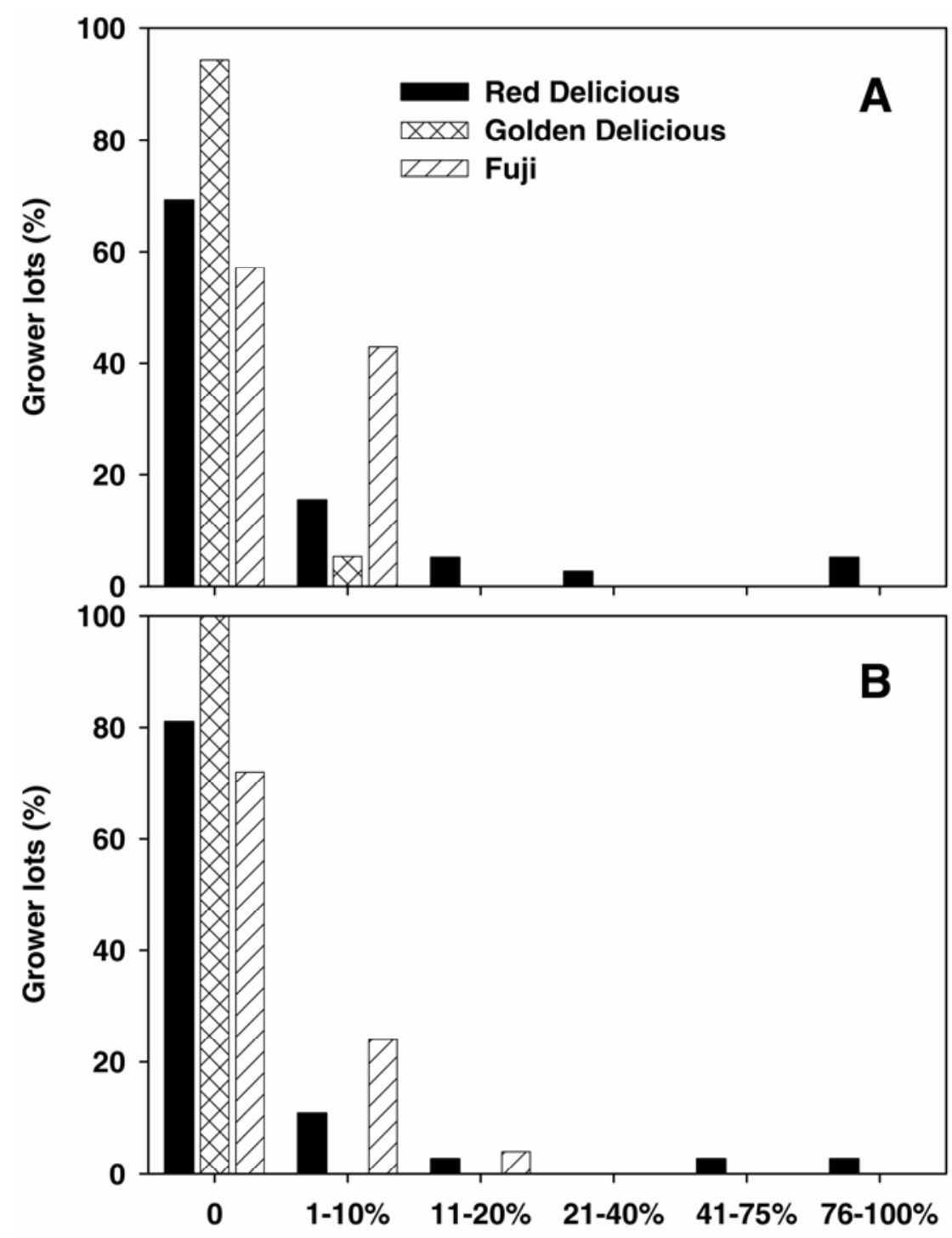

\section{Percentage of the total decayed fruit within a grower lot}

Fig. 2. Percentage of grower lots with different levels of fruit rot caused by Phacidiopycnis washingtonensis expressed as percentages of the total decayed fruit within a grower lot collected during March to August from three major apple varieties in 2004 (A) and 2005 (B). Seventy-two and 81 samples of approximately 50 decayed fruit each were collected in 2004 and 2005, respectively. Each sample represents the fruit from one unique orchard. 
by $P$. washingtonensis. $P$. piri is widespread in the major pear-producing areas in the U.S. Pacific Northwest and is commonly associated with dead bark, cankers, and twig dieback of pear trees (15). We observed $P$. washingtonensis on dead twigs of pear trees in a research orchard but did not observe the disease on pear fruit during a survey of postharvest diseases on d'Anjou pears conducted in 2001 and 2002 in Washington State (14). Thus, it appears that this new fruit rot disease is more commonly associated with apple than pear.

One distinct characteristic of this disease is the presence of brown or black specks at lenticels of decayed Red Delicious fruit. We propose "speck rot" as the name of this disease. The symptoms of this disease were similar to those of other spongy-type fruit rot diseases on apples,

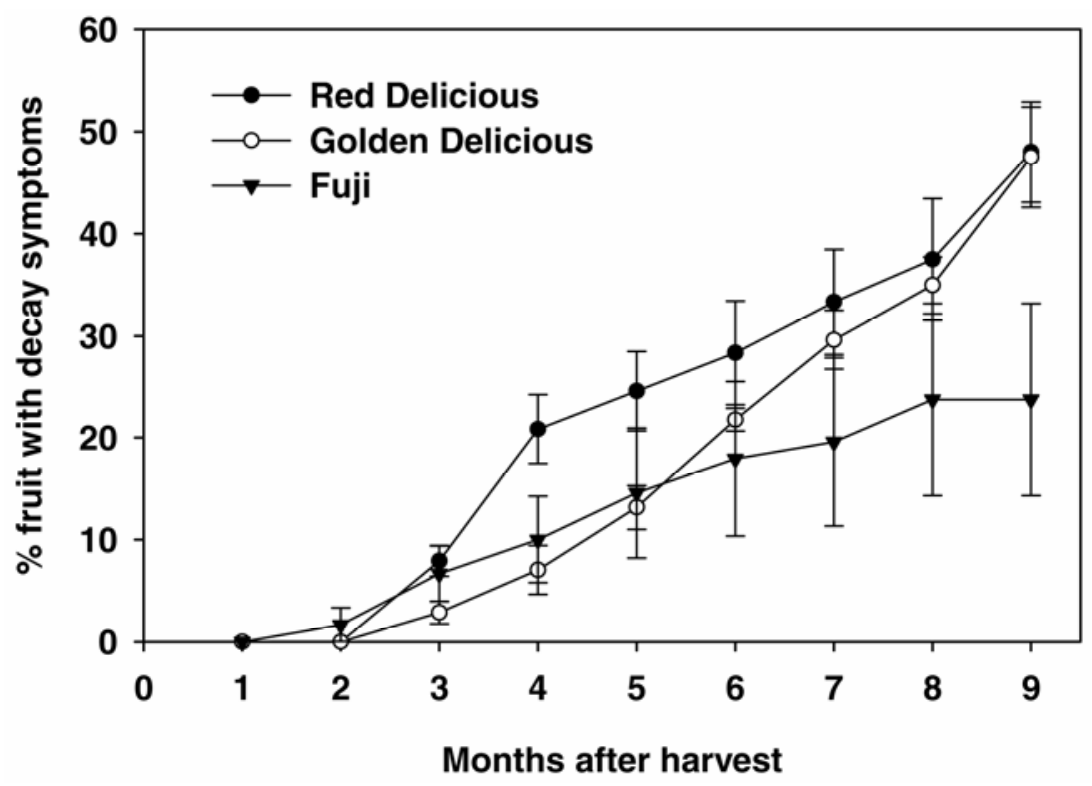

Fig. 3. Percentage of fruit with decay symptoms during storage on three apple varieties that were inoculated with conidial suspensions of Phacidiopycnis washingtonensis in the orchards at 1 and 2 weeks before harvest. All fruit after harvest were stored in regular atmosphere at $0^{\circ} \mathrm{C}$. Values are the means of pooled data from the two inoculation dates of the experiment (three replicates per variety on each inoculation date). Bar $=$ standard error of mean.

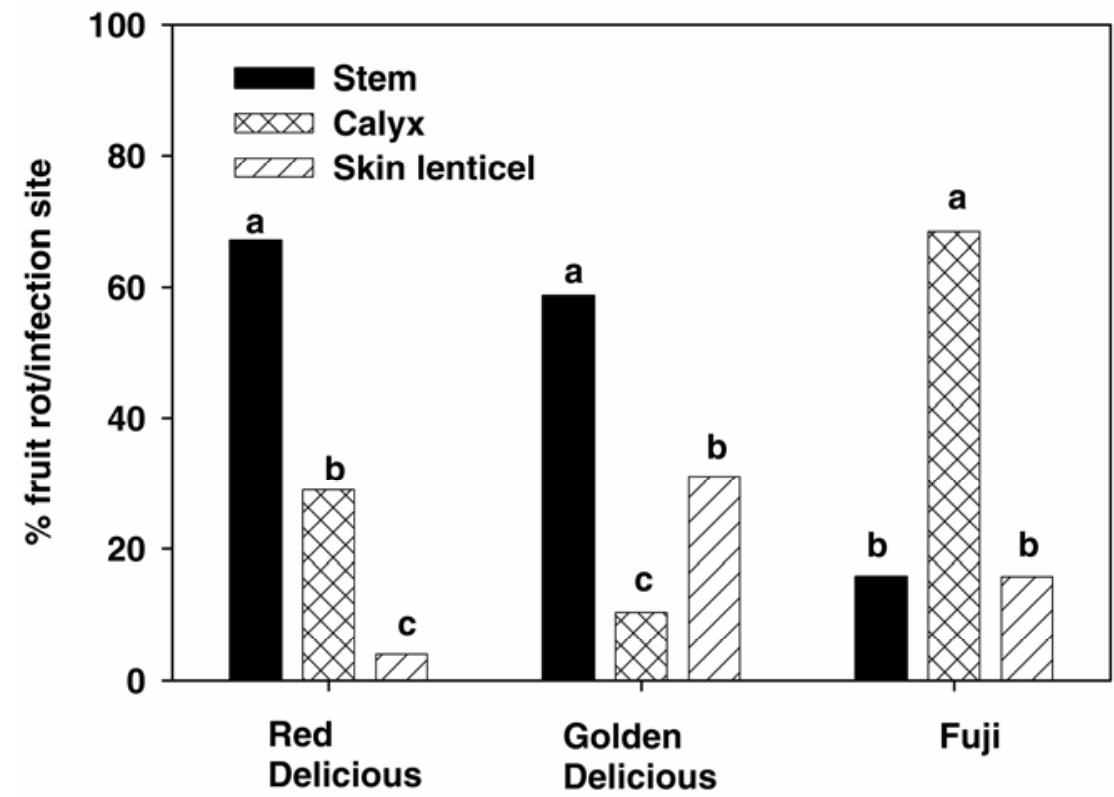

Fig. 4. Percentage of fruit rot originating from infections at the stem, calyx, or lenticels of fruit of three apple varieties by Phacidiopycnis washingtonensis. Fruit were inoculated with conidial suspensions of $P$. washingtonensis in the orchards at 1 or 2 weeks before harvest. All fruit after harvest were stored for 9 months in regular atmosphere at $0^{\circ} \mathrm{C}$. Values are the means of pooled data from two inoculation dates of the experiment (each variety with three replicates each with 50 fruit on each inoculation date). Bars with different letters within the same variety are significantly different based on the Fisher's least significant difference $(P=0.05)$.

such as gray mold and Sphaeropsis rot. Common characteristics of spongy-type fruit rot diseases on apples are that decayed fruit are spongy to firm and brown in the early stage of symptom development and that decayed flesh is not separable from the healthy tissue (8). On red apples, dark spots may persist around lenticels of gray mold-decayed fruit (8), but fruit decayed by $P$. washingtonensis also produced a distinct odor in advanced stages, which differentiated speck rot from gray mold. However, the odor of this new disease can be confused with that of Sphaeropsis rot. Therefore, identification of this disease based on symptoms alone is often difficult for fruit-quality control personnel in commercial fruit packinghouses. Isolation of the causal agent is recommended for confirmation of the disease. The symptoms of this disease also varied depending upon storage conditions. For example, in CA (1 to $2 \% \mathrm{O}_{2}$ and $0.5 \% \mathrm{CO}_{2}, 0^{\circ} \mathrm{C}$ ) the fungus rarely produced pycnidia on infected fruit, and the skin color of infected fruit remained light brown or brown. In our study, we stored the fruit that were inoculated with the pathogen in $\mathrm{RA}$ at $0^{\circ} \mathrm{C}$, and the fruit were wrapped with perforated polyethylene bags. We observed that the fungus often produced fluffy, white mycelia on the surface of decayed fruit, and later formed abundant pycnidia. In RA, the color of the decayed area initially was light brown to brown and later turned black, starting from the infection sites on the fruit.

Crabapple is commonly used as a source of pollen in apple production and might account for 5 to $10 \%$ of the trees in apple orchards. Xiao et al. (18) reported that $P$. washingtonensis is associated with a canker and twig dieback disease of crabapple trees in commercial apple orchards, and pycnidia of the fungus often were present on dead tissues of infected crabapple trees. We have also observed $P$. washingtonensis on dead tissues of apple trees (C. L. Xiao, unpublished). Because inoculum of the fungus was present in the orchard, we speculated that infection of fruit by the fungus occurred in the orchard. This is supported by our observations. During our survey, we observed the occurrence of this disease during storage on fruit that were directly stored in field bins and were not drenched with any postharvest fungicides prior to storage, indicating that infection of the stem and calyx of the fruit likely took place in the orchard because infection of fruit due to contamination during postharvest drenching or the packing process can be ruled out. In our orchard fruitinoculation study, fruit of three varieties inoculated with the fungus in the orchards did not exhibit any decay symptoms at harvest, but symptoms developed during storage. At harvest, we were able to reisolate the fungus from symptomless fruit that were inoculated with the fungus in the orchard. In a separate observation, we 
were able to isolate $P$. washingtonensis from naturally infected but symptomless fruit in early August (2.5 months before harvest) in a commercial Fuji orchard. The fruit harvested from the same orchard developed decay symptoms at $0^{\circ} \mathrm{C}$ during storage, and $P$. washingtonensis was isolated from decayed fruit (Y. K. Kim and C. L. Xiao, unpublished). These observations indicated that this new disease originated from infection of apple fruit by $P$. washingtonensis in the orchard leading to fruit rot symptoms during storage.

Although instances of severe losses of fruit caused by this disease were observed during our survey, the incidence of this disease as a percentage of the total decay observed over the 3-year survey was low. One of the factors limiting the development of this disease could be wetness duration required for fruit infection in orchard conditions. Xiao et al. (18) reported that at $20^{\circ} \mathrm{C}$ conidia of $P$. washingtonensis produce germ tubes after 16 to $18 \mathrm{~h}$ in $1 \%$ pear juice solution and after 10 to $12 \mathrm{~h}$ in $10 \%$ pear juice solution. The wetness duration required for conidial germination of $P$. washingtonensis is much longer than those of some other fruit-rotting pycnidial fungi on apple. For example, the wetness duration required for conidial germination is 5 to $6 \mathrm{~h}$ at $20^{\circ} \mathrm{C}$ for Sphaeropsis pyriputrescens (3), $4 \mathrm{~h}$ at 16 to $32^{\circ} \mathrm{C}$ for Botryosphaeria obtusa (1), and $1.5 \mathrm{~h}$ at $28^{\circ} \mathrm{C}$ for $B$. dothidea (12). The relationship between fruit infection and wetness duration on the fruit in field conditions has not been determined. In Washington State, apples are grown primarily in the central part of the state with a semiarid climate. In recent years, because of the increasing use of dwarf rootstocks, apple trees in modern orchards are smaller than those in traditional plantings, and more apple fruit on the trees could be directly exposed to sunlight in the summer, leading to the increase in sunburn on the fruit. Over-tree evaporative cooling has become a common practice for control of sunburn on apple fruit in this region (11). This practice could create prolonged wetness on the fruit conducive to the development of diseases. The impact of over-tree evaporative cooling on this disease and other diseases has not been evaluated.

We observed that the stem, calyx, and lenticel are the three major infection sites for $P$. washingtonensis on apple fruit, but it appears that there are differences among apple varieties. Stem-end rot was common on Red Delicious and Golden Delicious, whereas calyx-end rot was common on Fuji. Decay originating from infections of lenticels was commonly seen on Golden Delicious apples that were inoculated with the pathogen in the orchard, but less commonly seen on Red Delicious. We did not inoculate fruit earlier than 2 weeks before harvest. In commercial orchards, timing of infection and susceptibility of apple fruit to infection by the fungus during the fruitgrowing season has not yet been studied.

Control of postharvest diseases in pome fruits is a challenging task because multiple diseases often need to be targeted. Identifying target diseases is the first step to implementing relevant measures for disease control. Information generated in our study contributes to the knowledge base of postharvest diseases in apples.

\section{ACKNOWLEDGMENTS}

Plant Pathology New Series 0416, Project 0367, College of Agricultural, Human, and Natural Resource Sciences, Washington State University. We thank fruit packinghouses involved in the survey for assistance with sampling and R. J. Boal and L. J. Stone for technical assistance. This research was supported in part by the Washington Tree Fruit Research Commission and Washington State University Safe Food Initiative Funding Program.

\section{LITERATURE CITED}

1. Arauz, L. F., and Sutton, T. B. 1989. Temperature and wetness duration requirements for apple infection by Botryosphaeria obtusa. Phytopathology 79:440-444.

2. Heald, F. D., and Ruehle, G. D. 1931. The rots of Washington apples in cold storage. Ext. Bull., State College of Washington, Pullman.

3. Kim, Y. K., and Xiao, C. L. 2004. Influence of temperature, wetness duration, and relative humidity on conidial germination of Sphaeropsis pyriputrescens. (Abstr.) Phytopathology 94:S54.

4. Kim, Y. K., Xiao, C. L., and Rogers, J. D. 2004. Occurrence of Sphaeropsis pyriputrescens in apple in Washington State. (Abstr.) Phytopathology 94:S53-S54.

5. Meheriuk, M. 1993. CA storage conditions for apples, pears, and nashi. Pages 819-841 in: Proc. Int. Controlled Atmos. Res. Conf., 6th. Cornell University, Ithaca, NY.

6. National Agricultural Statistics Service, 2002. 2002 Washington Agricultural Statistics.

7. National Agricultural Statistics Service, 2005. 2005 Washington Agricultural Statistics.

8. Rosenberger, D. A. 1990. Gray mold. Pages 5556 in: Compendium of Apple and Pear Diseases. A. L. Jones and H. S. Aldwinckle, eds. American Phytopathological Society, St. Paul, MN.

9. Ruehle, G. D. 1930. Fungi which cause decay of apples in cold storage. Ph.D. diss. State College of Washington, Pullman.

10. Ruehle, G. D. 1931. New apple-rot fungi from Washington. Phytopathology 21:1141-1152.

11. Schrader, L. E., Zhang, J., and Duplaga, W. K. 2001. Two types of sunburn in apple caused by high fruit surface (peel) temperature. Online. Plant Health Progress. DOI:10.1094/PHP 2001-1004-01-RS.

12. Sutton, T. B. 1990 . White rot. Pages $16-18$ in: Compendium of Apple and Pear Diseases. A L. Jones and H. S. Aldwinckle, eds. American Phytopathological Society, St. Paul, MN.

13. Xiao, C. L. 2003. Management of postharvest fruit rots from orchard to storage. Pages 155160 in: Proc. Washington State Hortic. Assoc. 98th Annu. Meet.

14. Xiao, C. L., and Boal, R. J. 2004. Prevalence and incidence of Phacidiopycnis rot in d'Anjou pears in Washington State. Plant Dis. 88:413-418.

15. Xiao, C. L., and Boal, R. J. 2005. Distribution of Potebniamyces pyri in the U.S. Pacific Northwest and its association with a canker and twig dieback disease of pear trees. Plant Dis. 89:920-925.

16. Xiao, C. L., and Rogers, J. D. 2004. A postharvest fruit rot in d'Anjou pears caused by Sphaeropsis pyriputrescens sp. nov. Plant Dis. 88:114-118.

17. Xiao, C. L., Rogers, J. D., and Boal, R. J. 2004. First report of a new postharvest fruit rot on apple caused by Sphaeropsis pyriputrescens. Plant Dis. 88:223.

18. Xiao, C. L., Rogers, J. D., Kim, Y. K., and Liu, Q. 2005. Phacidiopycnis washingtonensis - A new species associated with pome fruits from Washington State. Mycologia 97:464-473. 